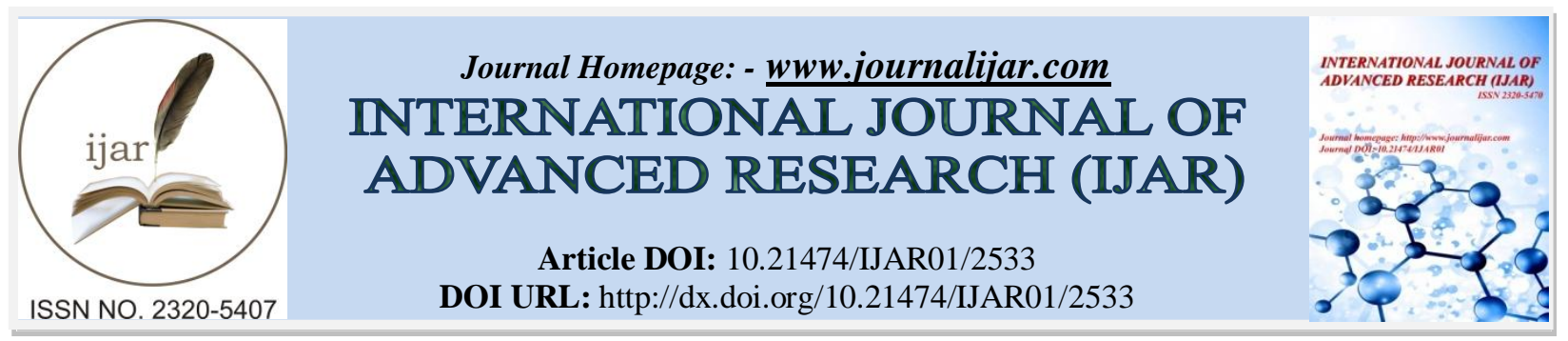

RESEARCH ARTICLE

\title{
PREVALENCE OF METABOLIC SYNDROME AMONG THE PATIENTS AND STAFF OF A TERTIARY CARE HOSPITAL IN RANCHI, INDIA.
}

Dr. Khageshwar Mahato ${ }^{1}$, Dr. Ajeet Kumar ${ }^{2}$, Dr. Sanjay Kumar ${ }^{3}$ and Dr. Sudhanshu Shekhar ${ }^{4}$.

1. Senior resident, Department of biochemistry, Lady Hardinge medical college, Delhi, India.

2. Professor \& HOD, Department of biochemistry, RIMS, Ranchi, India.

3. Associate professor, Department of Medicine, RIMS, Ranchi, India.

4. Junior resident, Department of biochemistry, RIMS, Ranchi, India.

\section{Manuscript Info}

Manuscript History

Received: 25 October 2016

Final Accepted: 23 November 2016

Published: December 2016

Key words:-

Metabolic syndrome, Cardio vascular disease, Type 2 Diabetes Mellitus, Hypertension, Obesity.

\section{Abstract}

Objectives: The prevalence of Metabolic Syndrome is rapidly increasing in India and other south Asian countries, leading to increased mortality and morbidity due to cardiovascular disease and Type 2 Diabetes mellitus. The following study was undertaken to assess the prevalence of Metabolic Syndrome among the patients and staff of a tertiary care hospital in Ranchi, India.

Materials and Methods: The study group comprised of 170 subjects with age group 18-60 years. The diagnosis of Metabolic Syndrome was done by NCEP ATP III (National Cholesterol Education Programme Third Adult Treatment Panel) criteria.

Results: The overall prevalence rate of Metabolic Syndrome was $20.6 \%$. Among males and females the prevalence was $18.8 \%$ and $23 \%$ respectively. A high prevalence rate was observed among older age group, high socio economic group, and sedentary life style group. Hypertension, Impaired glucose tolerance, Hypertriglyceridemia, low serum HDL Cholesterol level and obesity significantly contributed to increased risk of Metabolic Syndrome.

Conclusion: A high prevalence of Metabolic syndrome in this part of eastern India necessitates the early identification of cases so that preventive and corrective strategies could be deployed to prevent the occurrence of Metabolic Syndrome and its complications among individuals at risk.

Copy Right, IJAR, 2016,. All rights reserved.

\section{Manuscript:-}

The prevalence of Metabolic Syndrome is rapidly increasing in South Asian countries especially in India leading to increased morbidity and mortality due to CVD and Type2 diabetes mellitus(1,2).The Metabolic Syndrome(Syndrome x, Insulin resistance syndrome) consists of a constellation of metabolic abnormalities that confer increased risk of cardiovascular disease(CVD) and Type 2 diabetes mellitus(3). The metabolic syndrome is a cluster of risk factors like impaired glucose tolerance, abdominal obesity, atherogenic dyslipidemia and hypertension. It was estimated that $20-25 \%$ of the South Asians have developed Metabolic Syndrome and many more are at a great risk $(4,5)$. 
It is now well established that Metabolic Syndrome is a risk factor for increased cardiovascular mortality and morbidity. Cardiovascular disease accounts about $20 \%$ of all medical emergency admissions worldwide with a high mortality rate(6). A recent WHO study estimates that by 2020 ,CVD would be the leading cause of mortality in India with 2.6 million deaths $(7,8)$.Several studies showed that, overall the diabetics have a two fold increase in risk of coronary heart disease(9).Angiographic data of Indian patients with suspected coronary artery disease had revealed that triple vessel disease was much higher in diabetics as compared to non-diabetics to be followed by double vessel disease while single vessel disease was more common in non-diabetics(10).

The fundamental mechanism that leads to the Metabolic syndrome still remains unknown. Many researchers have tried to put forward possible hypotheses and explanations for the mechanism that links the different components of the Metabolic syndrome. Insulin resistance, leptin resistance, obesity, beta-cell dysfunction, sympathetic over activity, reduced serotonergic responsivity, thrifty genotypes and candidate genes are some of the etiological factors that have been proposed to cause Metabolic syndrome. Besides these there are various risk factors like advancing age, gender, race ,ethnicity, family history, food habits and addictions, physical inactivity, psychological and personality factors have also shown their association with Metabolic Syndrome. In Urban population a fast paced life, professional stress, physical inactivity and food habits have lead to emergence of a large number of risk factors of various diseases. Metabolic syndrome is very important disease associated with these changes in life style and food habits. The population of Ranchi, the capital city of Jharkhand in the pace of competing with the speed of westernization, is rapidly inducing changes in the life style and diet and thus was selected for the present study. The outcome of the present study will help in evaluating current situation, so that effective preventive and treatment strategies could be deployed.

\section{Materials and Methods:-}

The study was conducted by the department of Biochemistry in collaboration with the department of Medicine, Rajendra Institute of Medical Sciences, Ranchi. The study included 170 subjects and was selected randomly from the patients, visiting various OPDs. Hospital medical and paramedical staffs were also enrolled for the study.

The study was commenced after taking the approval from the ethical committee of the institution and the patients were enrolled in the study after getting informed consent. The inclusion criteria were all the subjects with age group 18-60 years. Patients with the history suggestive of chronic hepatic or renal disease which might affect biochemical parameters were excluded from study.

The diagnosis of the cases were done by NCEP ATP III (National Cholesterol Education Programme Third Adult Treatment Panel) criteria (Table-1)

Table-1:- Diagnosis of Metabolic Syndrome (NCEP ATP III criteria)

\begin{tabular}{|l|l|}
\hline \multicolumn{1}{|c|}{ The diagnosis of Metabolic Syndrome is made on the basis of presence of three or more of the following risk factors } \\
\hline \multirow{1}{|c|}{ Abdominal obesity } & $\begin{array}{l}\text { Waist circumference:- } \\
\text { Males }>102 \mathrm{~cm}(>40 \text { inches })\end{array}$ \\
& Females $>88 \mathrm{~cm}(>35$ inches $)$ \\
\hline Serum Triglyceride & $\geq 150 \mathrm{mg} / \mathrm{dl}$ \\
\hline HDL-Cholesterol & Males $<40 \mathrm{mg} / \mathrm{dl}$ \\
& Females $<50 \mathrm{mg} / \mathrm{dl}$ \\
\hline Blood Pressure & $\geq 130 / 85 \mathrm{~mm} \mathrm{Hg}$ \\
\hline Fasting Blood Glucose & $\geq 100 \mathrm{mg} / \mathrm{dl}$ \\
\hline
\end{tabular}

The study tool comprised of a interview, based on structured questionnaires which included subject identity, socioeconomic status (based on Kuppuswamy's socioeconomic scale) and details of classical risk factors like family history of hypertension, obesity, and diabetes .Questions also included items related to nutritional habits like vegetarian or non-vegetarian, addictions like chewing tobacco, smoking and alcoholism. Questions related to life style and physical activity was also recorded.

The anthropometric measurements were also recorded like, Body weight was determined with subjects wearing light clothes and no shoes or socks using an electronic balance and Height was determined using a wall mounted, non extendable measuring tape with subjects in standing position and feet together. Waist circumference was also 
measured with the help of a measuring tape at the level midway between the lowest rib and the iliac crest. Blood pressure was measured using a standard sphygmomanometer.

The subjects were asked not to take any fatty food in the previous night. A fasting (at least $10 \mathrm{hrs)} \mathrm{sample} \mathrm{was}$ collected under sterile condition into a plain vial and a fluoride vial. The method used for the estimation of serum triglyceride and HDL-Cholesterol was GPO-PAP (Glycerol-3-phosphate oxidase phenol aminophenazone) and Direct Clearance method respectively. GOD-PAP (Glucose oxidase phenol aminophenazine) method used for plasma glucose estimation. All the analytes were measured on Beckman Coulter AU 480 auto analyzer using commercial kits provided by Randox Industries, UK.

\section{Statistical analysis:-}

All statistical analysis were performed with the programme statistical package for the social science version 20.0(SPSS Inc, Chicago,Illinois).Significance difference in the proportion of potential life style factors by Metabolic Syndrome were estimated using Pearson's chi square test. A p value $<0.05$ was accepted as statistically significant. Unpaired T-test (gender) and one way analysis of variance (age) was performed. The prevalence of Metabolic syndrome was calculated using the prevalence rate formula that is number of patients per total number of all subjects at the time of study multiplied by 100 . Results were expressed as percentage (\%).

\section{Results:-}

The whole study group was comprised of 170 subjects. Amongst these $29.4 \%$ belonged to $18-30$ years age group, $38.8 \%$ belonged to $31-40$ years age group, $20.6 \%$ belonged to $41-50$ years age group and rest $11.2 \%$ belonged to 51 60 years age group. $56.5 \%$ of the study population were males and $43.5 \%$ were females. Vegetarians comprised of $30.6 \%$ and non-vegetarians were $69.4 \%$. Major proportion of the study population belonged to middle socioeconomic status (65.3\%).The high and low socio-economic status contributed $14.7 \%$ and $20 \%$ of the study population respectively. 55.3\% had moderately active life style. $25.9 \%$ had sedentary life style and $18.8 \%$ had active life style. $65.3 \%$ did not had any family history of diseases like hypertension, diabetes or obesity. Occupation wise $33.2 \%$ were housewives, $20.1 \%$ businessman, $19 \%$ were students, $14.3 \%$ were in service, $6.7 \%$ had agriculture as occupation and rest $6.7 \%$ were labourers.

Table -2:- Prevalence of Metabolic Syndrome among different demographic characteristics

\begin{tabular}{|c|c|c|c|c|c|c|}
\hline \multirow[t]{2}{*}{ Variable } & \multicolumn{2}{|c|}{$\begin{array}{l}\text { Subjects without MetS } \\
\quad(\mathrm{n}=135)\end{array}$} & \multicolumn{2}{|c|}{$\begin{array}{l}\text { Subjects with MetS } \\
\quad(\mathrm{n}=35)\end{array}$} & \multirow[t]{2}{*}{$\begin{array}{c}\text { Total } \\
(\mathrm{n}=170)\end{array}$} & \multirow[t]{2}{*}{$P$ value } \\
\hline & $\begin{array}{l}\text { Number of } \\
\text { subjects }\end{array}$ & $\begin{array}{l}\% \text { within the } \\
\text { group }\end{array}$ & $\begin{array}{l}\text { Number of } \\
\text { subjects }\end{array}$ & $\begin{array}{l}\% \text { within the } \\
\text { group }\end{array}$ & & \\
\hline \multicolumn{7}{|l|}{ Sex } \\
\hline $\begin{array}{c}\text { Male } \\
\text { Female }\end{array}$ & $\begin{array}{l}78 \\
57\end{array}$ & $\begin{array}{l}81.2 \% \\
77.0 \%\end{array}$ & $\begin{array}{l}18 \\
17\end{array}$ & $\begin{array}{l}18.8 \% \\
23.0 \%\end{array}$ & $\begin{array}{l}56.5 \% \\
43.5 \%\end{array}$ & 0.77 \\
\hline \multicolumn{7}{|l|}{ Age } \\
\hline $\begin{array}{l}18-30 \text { years } \\
31-40 \text { years } \\
41-50 \text { years } \\
51-60 \text { years }\end{array}$ & $\begin{array}{c}49 \\
59 \\
20 \\
7\end{array}$ & $\begin{array}{l}98.0 \% \\
89.4 \% \\
57.2 \% \\
36.8 \%\end{array}$ & $\begin{array}{c}1 \\
7 \\
15 \\
12\end{array}$ & $\begin{array}{r}2.0 \% \\
10.6 \% \\
42.8 \% \\
63.2 \%\end{array}$ & $\begin{array}{c}29.4 \% \\
38.8 \% \\
20.6 \% \\
11.2 \%\end{array}$ & 0.77 \\
\hline \multicolumn{7}{|l|}{ S/E Status } \\
\hline $\begin{array}{l}\text { High } \\
\text { Low } \\
\text { Middle }\end{array}$ & $\begin{array}{l}11 \\
32 \\
92\end{array}$ & $\begin{array}{l}45.0 \% \\
94.2 \% \\
82.9 \%\end{array}$ & $\begin{array}{c}14 \\
2 \\
19\end{array}$ & $\begin{array}{c}55.0 \% \\
5.8 \% \\
17.1 \%\end{array}$ & $\begin{array}{l}14.6 \% \\
20.0 \% \\
65.4 \%\end{array}$ & 0.01 \\
\hline \multicolumn{7}{|l|}{ Food Habit } \\
\hline $\begin{array}{l}\text { Non-veg } \\
\text { veg }\end{array}$ & $\begin{array}{l}93 \\
42\end{array}$ & $\begin{array}{l}78.8 \% \\
80.8 \% \\
\end{array}$ & $\begin{array}{l}25 \\
10 \\
\end{array}$ & $\begin{array}{l}21.2 \% \\
19.2 \% \\
\end{array}$ & $\begin{array}{l}69.4 \% \\
30.6 \% \\
\end{array}$ & 0.09 \\
\hline \multicolumn{7}{|l|}{ Life Style } \\
\hline $\begin{array}{r}\text { Active } \\
\text { Mod.Active } \\
\text { Sedentary }\end{array}$ & $\begin{array}{l}29 \\
75 \\
31\end{array}$ & $\begin{array}{l}89.5 \% \\
79.5 \% \\
70.5 \%\end{array}$ & $\begin{array}{c}3 \\
19 \\
13\end{array}$ & $\begin{array}{l}10.5 \% \\
20.5 \% \\
29.5 \%\end{array}$ & $\begin{array}{l}18.9 \% \\
55.3 \% \\
25.8 \%\end{array}$ & 0.002 \\
\hline
\end{tabular}


MetS-Metabolic Syndrome, S/E Status-Socioeconomic status, Non-veg- Non-vegetarian ,veg- Vegetarian, Mod. Active- Moderately Active.

Table 2 showed the prevalence was highest (63.2\%), among 51-60 age group. Prevalence in 18-30 years age group was lowest (2\%). The prevalence among females was $23.0 \%$ and among males was $18.8 \%$. A very high prevalence was observed in the high socioeconomic group, $(55.0 \%)$. The prevalence in the middle and low socioeconomic group was $25.0 \%$ and $5.8 \%$ respectively. Among vegetarian the prevalence was $19.2 \%$ and among non-vegetarian the prevalence was $21.2 \%$. Prevalence among active group was $10.5 \%$. Prevalence among moderately active and sedentary lifestyle was $20.5 \%$ and $29.5 \%$ respectively. The overall prevalence of Metabolic Syndrome in the state of Ranchi was $20.6 \%$.

Table-3 shows the prevalence of important study clinical characteristics among diagnosed cases of Metabolic Syndrome and among normal subjects.

Table 3:- Prevalence of Metabolic Syndrome among different clinical characteristics

\begin{tabular}{|l|c|c|}
\hline \multicolumn{1}{|c|}{ Clinical characteristics } & Normal subjects & Cases of Metabolic syndrome \\
\hline $\begin{array}{l}\text { Prevalence(\%) of Hypertensives (B.P. } \geq 130 / 85 \mathrm{~mm} \\
\text { of Hg) }\end{array}$ & $24.5 \%$ & $75.5 \%$ \\
\hline Prevalence of impaired glucose tolerance ( FPG $\geq 110$ ) & $29.9 \%$ & $70.1 \%$ \\
\hline $\begin{array}{l}\text { Prevalence of Hypertriglyceridemia } \\
(\geq 150 \mathrm{mg} / \mathrm{dl})\end{array}$ & $15.0 \%$ & $85.0 \%$ \\
\hline $\begin{array}{l}\text { Prevalence of Low HDL } \\
\text { HDL < 40 mg/dl ) }\end{array}$ & $26.8 \%$ & $73.2 \%$ \\
\hline Prevalence of Obesity ( BMI $\geq 30)$ & $8.8 \%$ & $91.2 \%$ \\
\hline
\end{tabular}

B.P.-Blood pressure, FPG- Fasting plasma glucose, HDL- High density lipoprotein BMI- Body mass index.

\section{Discussion:-}

The prevalence of Metabolic syndrome in India has shown an exponential increase in last few years in both rural and urban areas. In different parts of India the figure of Metabolic syndrome ranges from $11 \%$ to $41 \%$ ( 11). After the analysis of our data, the results showed that 35 out of a total 170 study subjects were diagnosed as cases of Metabolic syndrome based upon NCEP ATP III diagnostic criteria. It was concluded that the prevalence of Metabolic Syndrome among the patients and staff in Rajendra institute of medical sciences, Ranchi (Tertiary care Hospital) was $20.6 \%$.

The results obtained by Sawant et al showed a prevalence of $19.52 \%$ in an urban population in western India, which is comparable to the results obtained by our study (12). Our study findings do corroborate with the findings of Deepa et al (13). Likewise, a prevalence study of urban community in northern India reported a prevalence of 22.37\% for Metabolic syndrome (14).Similar findings were also observed by Mishra et al who showed that one third of the urban populations in India's major cities had Metabolic Syndrome (15).Study done by Prasad DS et al found the prevalence of Metabolic syndrome among urban eastern Indian population was $33.5 \%$ which is greater than our findings (2).

As far western countries are concerned, according to a recent data, from 2003-2012 the overall prevalence of Metabolic Syndrome in the United states was reported to be $33 \%(16)$ and the similar results were also found by Fernandez et al among adult Spanish population(17). A prevalence study on adult Chinese population concluded the age standardised prevalence rate was $21.3 \%$ (18). The relatively low prevalence of our study could be attributed to the life style patterns and socio-economic/cultural factors, as major proportion of the Ranchi population is contributed by the Tribal population.

Females $(23 \%, \mathrm{n}=17 / 74)$ had higher rates of Metabolic Syndrome than males $(18.8 \%, \mathrm{n}=18 / 96)$, though the difference was not statistically significant. Our study findings are comparable with the findings of Prasad et al (2), who observed significantly higher prevalence among females(52.2\%) than males(34.2\%).Study results from Chennai by Ramchandran et al showed presence of Metabolic syndrome 36.4\% among men and 46.5\% among women.(19). Similar study results were observed by Sidorenkov O et al on Northwest Russian population (20).Many studies in Indian subcontinent had shown, women had a higher prevalence of Metabolic syndrome (21, 22).A little 
difference among men (24.0\%) and women (23.4\%) observed in NHANES III data (23).But there are some studies in India which show greater prevalence among males than females (24). In the present study, a higher prevalence among women could be understood by the facts that the majority of the population belong to middle socio economic group and most of the women were housewives. Their life styles are mostly inactive. Dallongerville et al suggested that elevated body weight and waist girth and the low HDL are significantly larger contributors to the metabolic syndrome in women than men.(25).

The present study also showed that there was an increase in prevalence with the increasing age. Maximum Prevalence was observed in subjects above 51 years $(63.2 \%)$ and minimum in the age group 18-30 years $(0.6 \%)$. This finding is in conformity with Ford ES et al who found an increase in prevalence of the Metabolic syndrome among US adults.(26). They found that the prevalence was increased from $6.7 \%$ among people aged $20-29$ years to $43.5 \%$ for participants aged 60-69 years. This trend was also supported by another study by Ervin RB et al which showed about $20 \%$ of males and $16 \%$ of the females under 40 years of age met the criteria and $52 \%$ of males and $54 \%$ of females 60 years or above met the criteria for Metabolic syndrome. (27). The higher prevalence in the older age group is obvious as the number of the risk factors increases with age. Similar studies were obtained by Carnethon et al who suggested that young adults are at a reduced risk of developing Metabolic syndrome due to maintained regular physical activity (28).

In our study the prevalence of Metabolic Syndrome was very high in high socioeconomic group (55\%, 14/25).The prevalence was $5.8 \%(2 / 34)$ and $17.1 \%(19 / 111)$ in low socioeconomic group and middle socioeconomic group respectively. The difference was statistically significant $(\mathrm{p}=0.01)$. Our results are found to be in conformation with the findings obtained by Prasad et al in urban eastern population, where he observed significantly high prevalence (47.8\%) in high socio economic strata (2).Similar results were also obtained by Deepa R et al from Chennai showing $18.7 \%$ prevalence of Metabolic syndrome in upper socioeconomic strata and 6.5\% in low socioeconomic strata (29). The high prevalence among high and middle socio economic group can be attributed to their dietary habits and life style. Dietary consumption of high saturated fats and cholesterol along with low in fibres and antioxidants puts them at risk of developing Metabolic syndrome. Besides this maladaptation, stressful life, alcoholism and smoking are additional contributory factors.

The results obtained in Ranchi are quite understandable as middle and high socioeconomic group here are undergoing a cultural transition which includes westernization of lifestyle and diet in addition to new addictions and professional stress. But this trend in India is different from western countries as reflected by study done by Carnethon et al in US population.(28).In India the prevalence of risk factors like obesity and dyslipidemia are more frequent in higher socioeconomic group where as in the US they are more frequent in lower socioeconomic groups. Analysis based upon food habits showed prevalence among vegetarians and non-vegetarians were $19.2 \%$ and $21.2 \%$ respectively. The difference was not statistically significant $(\mathrm{p}=0.90)$. The equally high prevalence among vegetarians can be attributed to their food habits which are full of sugars and refined carbohydrates.

The prevalence of Metabolic syndrome was highest $(29.5 \%)$ in sedentary life style group whereas prevalence was least $(10.5 \%)$ in active life style group. In the present study the difference was statistically significant $(\mathrm{p}=0.002)$. The reason is obvious as physical activity helps in reducing weight and maintaining a lower body mass index. Our study results are supported by result findings of Carnethon et al (28).

Various clinical parameters used to diagnose Metabolic Syndrome like Hypertension, Impaired glucose tolerance, Serum triglyceride level, Serum HDL-Cholesterol level and obesity also measured. The prevalence of Metabolic syndrome among subjects with hypertension was $75.5 \%$, with impaired glucose tolerance was $70.1 \%$, with raised level of serum triglyceride was $85 \%$, with low HDL-Cholesterol was $73.2 \%$ and among obese was $91.2 \%$.The study of these parameters was done to understand the predisposing risk factors and etiopathogenesis of Metabolic syndrome as it is crucial for guiding effective strategies for prevention and treatment of Metabolic Syndrome.

\section{Conclusion:-}

Our study suggested, a high prevalence (20.6\%) of Metabolic syndrome in Ranchi that means one out of every five adults in Ranchi is at risk of developing type 2 diabetes mellitus and cardiovascular disease. Women are equally as prone as men. The study also revealed an increase in prevalence of Metabolic Syndrome with the increasing age. Highest prevalence was observed in the age group above 51 years suggesting that this group has increased risk of developing Type 2 diabetes and cardiovascular disease. 
Highest prevalence was observed among high socioeconomic group which could be attributed to the dietary habits and the sedentary life style group also had maximum prevalence due to less physical activity. The subjects with Hypertension, raised level of serum triglyceride, low level of serum HDL-Cholesterol and obese had high prevalence as these clinical parameters contribute to the development of Metabolic Syndrome.

According to our study a high prevalence of Metabolic Syndrome was found, so an early identification and preventive actions should be planned to prevent the occurrence of Metabolic Syndrome among individuals at risk.

Strength of our study includes a well characterised study population and standardized techniques to measures various parameters of the study and a small sample size from the local area was included, which was the only limitation of our study. It was hospital based study so large prospective follow up studies covering wide geographical area should be undertaken to validate the findings.

\section{Conflict of Interest:-}

No conflict of interest to declare.

\section{References:-}

1. MohanV.Rao GHR. Type2 Diabetes in South Asians 1st ed. New Delhi: South Asian Society on Atherosclerosis and Thrombosis; 2007.

2. Prasad DS, Kabir Z, Dash AK, Das BC. Abdominal obesity, an independent cardiovascular risk factor in Indian subcontinent: A clinico epidemiological evidence summary. Journal of cardiovascular disease research. 2011 Dec 31; 2(4):199-205.

3. Grundy SM. Metabolic syndrome: connecting and reconciling cardiovascular and diabetes worlds. Journal of the American College of Cardiology. 2006 Mar 21; 47(6):1093-100.

4. Nestel P, Lyu R, Low LP, Sheu WH, Nitiyanant W, Saito I, Tan CE. Metabolic syndrome: recent prevalence in East and Southeast Asian populations. Asia Pacific journal of clinical nutrition. 2007 Jun 1; 16(2):362-7.

5. Eapen D, Kalra GL, Merchant N, Arora A, Khan BV. Metabolic syndrome and cardiovascular disease in South Asians. Vasc Health Risk Manag. 2009; 5:731-43.

6. Capewell S, McMurray J. Chest pain-please admit: is there an alternative?.BMJ-British Medical JournalInternational Edition. 2000 Apr 8; 320(7240):951-.

7. Reddy KS, Prabhakaran D, Chaturvedi V, Jeemon P, Thankappan KR, Ramakrishnan L, Mohan BM, Pandav CS, Ahmed FU, Joshi PP, Meera R. Methods for establishing a surveillance system for cardiovascular diseases in Indian industrial populations. Bulletin of the World Health Organization. 2006 Jun; 84(6):461-9.

8. Goenka S, Prabhakaran D, Ajay VS, Reddy KS. Preventing cardiovascular disease in India-translating evidence to action. Current science. 2009 Aug 10; 97(3):367-77.

9. Stamler J, Vaccaro O, Neoton JD et al. Cardiovascular mortality for man screened in multiple risk factor intervention trial. Diabetes care 1993:16:434-444

10. PatnaikUK.Indian scenario 2000: 49-53

11. Misra A, Khurana L. Obesity and the metabolic syndrome in developing countries. The Journal of Clinical Endocrinology \& Metabolism. 2008 Nov; 93(11_supplement_1):s9-30.

12. Sawant A, Mankeshwar R, Shah S, Raghavan R, Dhongde G, Raje H, D'souza S, Subramanium A, Dhairyawan P, Todur S, Ashavaid TF. Prevalence of metabolic syndrome in urban India. Cholesterol. 2011 May 19; 2011.

13. Deepa M, Farooq S, Datta M, Deepa R, Mohan V. Prevalence of metabolic syndrome using WHO, ATPIII and IDF definitions in Asian Indians: the Chennai Urban Rural Epidemiology Study (CURES-34). Diabetes/metabolism research and reviews. 2007 Feb 1; 23(2):127-34.

14. Ravikiran M, Bhansali A, Ravikumar P, Bhansali S, Dutta P, Thakur JS, Sachdeva N, Bhadada S, Walia R. Prevalence and risk factors of metabolic syndrome among Asian Indians: a community survey. Diabetes research and clinical practice. 2010 Aug 31; 89(2):181-8.

15. Misra A, Khurana L. The metabolic syndrome in South Asians: epidemiology, determinants, and prevention. Metabolic syndrome and related disorders. 2009 Dec 1S; 7(6):497-514.

16. Aguilar M, Bhuket T, Torres S, Liu B, Wong RJ. Prevalence of the metabolic syndrome in the United States, 2003-2012.Jama. 2015 May 19; 313(19):1973-4.

17. Fernández-Bergés D, de León AC, Sanz H, Elosua R, Guembe MJ, Alzamora M, Vega-Alonso T, FélixRedondo FJ, Ortiz-Marrón H, Rigo F, Lama C. Metabolic syndrome in Spain: prevalence and coronary risk associated with harmonized definition and WHO proposal. DARIOS study. Revista Española de Cardiología (English Edition). 2012 Mar 31; 65(3):241-8. 
18. Xi B, He D, Hu Y, Zhou D. Prevalence of metabolic syndrome and its influencing factors among the Chinese adults: the China Health and Nutrition Survey in 2009. Preventive medicine. 2013 Dec 31; 57(6):867-71.

19. Ramachandran A, Snehalatha C, Satyavani K, Sivasankari S, Vijay V. Metabolic syndrome in urban Asian Indian adults - a population study using modified ATP III criteria. Diabetes research and clinical practice. 2003 Jun 30; 60(3):199-204.

20. Sidorenkov O, Nilssen O, Brenn T, Martiushov S, Arkhipovsky VL, Grjibovski AM. Prevalence of the metabolic syndrome and its components in Northwest Russia: the Arkhangelsk study. BMC Public Health. 2010 Jan 19; 10(1):1.

21. Khanam MA, Qiu C, Lindeboom W, Streatfield PK, Kabir ZN, Wahlin Å. The metabolic syndrome: prevalence, associated factors, and impact on survival among older persons in rural Bangladesh. PLoS One. 2011 Jun 15;6(6):e20259.

22. Jesmin S, Islam MR, Islam AS, Mia MS, Sultana SN, Zaedi S, Yamaguchi N, Iwashima Y, Hiroe M, Watanabe T. Comprehensive assessment of metabolic syndrome among rural Bangladeshi women. BMC Public Health. 2012 Jan $19 ; 12(1): 1$.

23. Park YW, Zhu S, Palaniappan L, Heshka S, Carnethon MR, Heymsfield SB. The metabolic syndrome: prevalence and associated risk factor findings in the US population from the Third National Health and Nutrition Examination Survey, 1988-1994. Archives of internal medicine. 2003 Feb 24;163(4):427-36.

24. Chow CK, Naidu S, Raju K, Raju R, Joshi R, Sullivan D, Celermajer DS, Neal BC. Significant lipid, adiposity and metabolic abnormalities amongst 4535 Indians from a developing region of rural Andhra Pradesh.Atherosclerosis. 2008 Feb 29; 196(2):943-52.

25. Dallongeville J, Cottel D, Arveiler D, Tauber JP, Bingham A, Wagner A, Fauvel J, Ferrieres J, Ducimetiere P, Amouyel P. The association of metabolic disorders with the metabolic syndrome is different in men and women. Annals of nutrition and metabolism. $2004 \mathrm{Feb} 20 ; 48(1): 43-50$.

26. Ford ES, Giles WH, Mokdad AH. Increasing prevalence of the metabolic syndrome among US adults. Diabetes care. 2004 Oct 1; 27(10):2444-9.

27. Ervin RB. National Health Statistics Reports. Prevalence of Metabolic Syndrome among Adults. 2009; 20:2003-6.

28. Carnethon MR, Loria CM, Hill JO, Sidney S, Savage PJ, Liu K. Risk Factors for the Metabolic Syndrome the Coronary Artery Risk Development in Young Adults (CARDIA) study, 1985-2001. Diabetes care. 2004 Nov 1; 27(11):2707-15.

29. Deepa R, Shanthirani CS, Premalatha G, Sastry NG, Mohan V. Prevalence of insulin resistance syndrome in a selected south Indian population--the Chennai urban population study-7 [CUPS-7]. Indian Journal of Medical Research. 2002 Mar 1; 115:118. 